\title{
Educational and social characteristics of children with asthma
}

\author{
ROSS G. MITCHELL and BLANCHE DAWSON \\ From the Department of Child Health, University of Aberdeen, Aberdeen
}

\begin{abstract}
Mitchell, R. G., and Dawson, B. (1973). Archives of Disease in Childhood, 48, 467. Educational and social characteristics of children with asthma. Asthma was found to affect $4 \cdot 8 \%$ of Aberdeen schoolchildren aged 10 to 15 years, the ratio of affected boys to girls being $2 \cdot 2: 1$.

In the majority of children, asthma caused frequent absence from school in the early years: at the time of the study there was still some adverse effect on education in half of the children with severe asthma but in only a minority of those with moderate or mild asthma.

There was an excess of severe asthma in the children of semi- and unskilled manual workers (social classes IV and V). Children with severe asthma tended to come from large families, regardless of social class.

The children with asthma had a higher mean IQ than the general study population.
\end{abstract}

Children with asthma are frequently absent from school because of acute attacks or exacerbations of asthma, intercurrent infections to which they are often predisposed by poor physique, and the need to attend clinics and therapy sessions. It is generally believed that such educational disadvantage is augmented in some children by neurotic characteristics enhanced by dependence on overprotective parents, but that these adverse factors are offset to some extent by superior intelligence, personality traits of ambition and conscientiousness, and a better-than-average social background. There is little real evidence for these beliefs which depend largely on clinical impressions of particular children and selected series of patients (Dubo et al., 1961). It is, therefore, important to try to establish the true picture as objectively as possible, and this can only be achieved by obtaining information about an unselected population of children with asthma. The study from which the data presented here are derived was not undertaken specifically from the educational point of view but rather to present a comprehensive picture of childhood asthma in one city (Dawson et al., 1969). Nevertheless, some of the information obtained has a direct bearing on the educational problems of children with asthma.

Received 3 October 1972.

\section{Methods and procedure}

The study formed part of a larger survey conducted in association with the Medical Research Council's Medical Sociology Research Unit. The population studied consisted of all children attending Aberdeen primary schools in 1962 and still resident in Aberdeen in 1964, when a 1 in 5 random sample of the children was made for interview. The sample comprised 2743 children, of whom 2511 were actually interviewed.

The initial interviews were conducted by specially trained interviewers, using a detailed questionnaire which included a simply-worded medical section. The questionnaire was completed while interviewing the family in their own home, the source of the information being the child s parent or guardian.

The subjects covered related to parents as well as to children. Questions were phrased to include school interests and hobbies, membership of youth clubs and organizations, attendance at church and Sunday school, use of public libraries, and reading of educational magazines. Each parent was asked a series of questions indicating the sort of job or career that they would prefer their child to have when he left school. A series of 10 questions was used to ascertain parental attitudes on some controversial subjects relating to school.

The occupation of the child's father was recorded at the time of interview and coded according to the Registrar General's 'classification of occupations': class III (skilled workers) was further subdivided into its manual and nonmanual categories. Because of small numbers we have used a 3-class breakdown, namely nonmanual (class I and II and the nonmanual 
segment of III), skilled manual (remainder of class III), and semi- and unskilled manual (classes IV and V).

In addition to the information obtained at interview, results of the Moray House Picture Intelligence Test No. 1 were available for the total population of children at risk-the children had been tested at the age of $7+$ years.

For each child in the study, a behaviour scale, designed to detect neurotic and antisocial behaviour, was completed by the parent without help from the interviewer. This was the Aberdeen-London Behaviour Scale A, designed by Dr. Michael Rutter (Rutter, Tizard, and Whitmore, 1970).

We defined asthma as 'recurrent dyspnoea of an obstructive type without other demonstrable cause'. All children considered to conform to this definition were graded according to severity (Dawson et al., 1969) and then asked to attend for history and examination, including questions on the relation of the asthmatic attacks to attendance and performance at school. The ages of the children at the time of examination ranged from 10 to 15 years.

\section{Results}

After examining 288 children suspected of asthma on the basis of the questionnaire, the diagnosis was confirmed in 121 ( 84 boys and 37 girls) giving a prevalence rate of $4.8 \%$. In 50 cases the asthma was graded as mild, in 51 as moderate, and in 20 as severe. Of the 121 children, 98 had experienced their first asthmatic attack by the age of school entry (5 years): asthma did not develop until 9 years of age or later in 14 children.

School attendance. More than trivial absence from school was reported in 88 of the 121 children: of the 88,31 had mild, 41 moderate, and 16 severe asthma. Most of the mildly or moderately affected children had varying periods of absence in the first three school years, but the majority were managing to attend fairly regularly by the time of interview. Half of the severely affected children were still having their education seriously interrupted because they were incapacitated during acute attacks (Table). The impression gained in the majority of these cases was that the children were keen to attend school despite their disability.
Physical education. When asked about participation in physical education at school, there was a variation of answers from mild to severe cases. The children with mild and moderate asthma on the whole managed to do gymnastics or drill when not actually wheezing, but many said that strenuous exercise, particularly football or athletics, was likely to precipitate an attack. Some of the severely affected children took part in physical education classes when they were relatively well, but in most cases participation was limited by awareness that quite a small amount of exertion could bring on acute symptoms.

Family and social background. There was an excess of severe cases of asthma in the semi- and unskilled manual class $(P<0 \cdot 005)$ and a trend for children with severe asthma to come from larger families, i.e. with 4 or more children $(P<0.05)$, mild cases occurring mainly in small families regardless of social class.

The proportion of children who were the second child of the family was higher in the asthmatic group than in the general child population in the study: $44 \%$ of the children with asthma were second children, compared with $31 \%$ in the general population $(P<0 \cdot 005)$.

Intelligence. Intelligence measured at $7+$ years showed that there was a higher mean IQ in the children with asthma than in the general child population in all social classes: this was particularly evident in the children of the semiand unskilled manual class, where the mean IQ of the child with asthma was 102, compared with 95 for the general population $(P<0 \cdot 01)$.

Homework. The parents of all the children in the study reported on the amount of homework done by their children. Different amounts were coded from less than 20 minutes to more than $1 \frac{1}{2}$ hours. There was no difference between the asthma group and the study population, for they showed a similar wide variation according to age, school, and home background.

TABLE

Parents' estimation of adverse effect on schooling of asthma of different grades of severity

\begin{tabular}{|c|c|c|c|c|}
\hline & Mild & Moderate & Severe & Total \\
\hline $\begin{array}{l}\text { Little or no effect } \\
\text { Effect mainly in first } 3 \text { school years } \\
\text { Continuing effect at time of interview }\end{array}$ & $\begin{array}{r}19 \\
23 \\
8\end{array}$ & $\begin{array}{r}10 \\
36 \\
5\end{array}$ & $\begin{array}{r}4 \\
6 \\
10\end{array}$ & $\begin{array}{l}33 \\
65 \\
23\end{array}$ \\
\hline Total & 50 & 51 & 20 & 121 \\
\hline
\end{tabular}


Interests outside school. Attendance at church and Sunday school by the children with asthma was similar to that of the whole population of children: $25 \%$ attended church regularly and $55 \%$ attended Sunday school regularly. Use of public libraries was also similar in the two groups: $60 \%$ used a library regularly, i.e. borrowed a book at least once a month, 15 to $20 \%$ occasionally, and $20 \%$ not at all. The parents of the children with asthma regularly bought more educational magazines than did the parents of the general child population $(P<0.05)$ : this was most evident in the moderate and severe groups but the total numbers were small. There was no difference in membership of youth clubs and organizations, including Scouts and Guides, Wolf Cubs and Brownies, Lifeboys, etc., $30 \%$ of each group belonging to some organization.

Differences between the children with asthma and their fellows were apparent when we considered their spare time activities and hobbies: $70 \%$ of the whole study group indulged in outdoor activities such as field sports, games, or camping, but the percentage was only $40 \%$ in the asthma group which enjoyed quieter and more sedentary hobbies such as model-building, painting, reading, and card games.

Parental attitudes. When asked what kind of career or job they would like their children to have on leaving school, parents of asthma and control groups answered in a similar way: $37 \%$ preferred that their children enter a profession, $31 \%$ wished them to enter clerical or distributive trades, and the remainder were undecided.

Posed a choice of three types of job (1) a secure job, (2) a job with good prospects for advancement, (3) a job with good pay, more of the parents in the asthma group said they would prefer a job with good pay for their child, but the difference was not statistically significant.

Parental opinions were asked for on the following statements.

(1) 'You can't get anywhere without a grammar school education these days.'

(2) 'More time should be given to religious instruction in schools.'

(3) 'Corporal punishment (the strap) should be banned in schools'.

(4) 'Parents should be encouraged to visit the school at least once per term.'

(5) 'A child of 10 should be left to cope with nearly all his own problems by himself.'

(6) 'Boys and girls should go to separate secondary schools.'

(7) 'Bringing up the children is mother's job.'
(8) 'Young people who break the law should be punished much more severely than they are.'

(9) 'The 11-plus (transfer) examination should be abolished.'

(10) 'Sex education in schools probably does more harm than good.'

Some of the answers showed differences between the asthma group and the general population. More parents of children with asthma agreed with opinion (1) $(\mathrm{P}<0 \cdot 05)$. On opinion (3), 'corporal punishment should be banned in schools', more parents in the asthma group were in favour of retaining the strap $(P<0.05)$.

More parents of children with asthma thought that there should be separation of the sexes in secondary schools: fewer thought that 'bringing up children is mother's job', but the differences here were not significant.

\section{Discussion}

Prevalence. There have been few comprehensive studies of asthma in childhood and most of these have had a special purpose, searching for one or more aspects of the picture of the child with asthma. In many of the surveys the prevalence rates found were less than that of our study $(4 \cdot 8 \%)$. The Scandinavian surveys of Kraepelien (1954), Peltonen, Kasanen, and Peltonen (1955), and Eriksson-Lihr (1955) gave prevalence rates of $0.7,0.8$, and $0.7 \%$, respectively. In his survey of Birmingham schoolchildren, Smith (1961) found a prevalence rate for definitely diagnosed asthma of $1.8 \%$, though 12 years later this had increased to $2 \cdot 3 \%$ (Smith, Harding, and Cumming, 1971). Graham et al. (1967) reported a $2 \cdot 3 \%$ prevalence rate for childhood asthma in the Isle of Wight. The results of two American surveys are close to the Aberdeen prevalence rate of $4 \cdot 8 \%$. The study of asthma in the total community of Tecumseh, Michigan (Broder, Barlow, and Horton, 1962), showed a comparable prevalence in similar age groups; while Arbeiter (1967), in a study of allergy in schoolchildren in Munster, Indiana (an upper-middle income suburb of Chicago) found a prevalence of asthma of $4.9 \%$. From Melbourne, Australia, Williams and McNicol (1969) reported a rate of $3.7 \%$.

Many surveys have used school medical record cards for calculating prevalence rates. If we had done this, a substantial number of cases would have been missed as only 36 of the 121 children had asthma recorded on their cards.

Family and social background. Two studies, those of Peltonen et al. (1955) and Freeman and Johnson (1964), have shown that allergy is more 
common in the children of college graduates than in those of manual workers, but these data referred to total allergy and did not deal with asthma in particular. Our finding that severe asthma is more often found in the children of semiskilled and unskilled manual workers differs from the results of the Isle of Wight study (Graham et al., 1967) where an excess of children in social classes $I$ and II and an underrepresentation of social classes IV and $\mathrm{V}$ were found among the children with asthma. The Isle of Wight study reported a lower ratio of boys to girls than we did and the authors suggested that this might have been due to the fact that they had more mild cases. Both Smith (1961) and we ourselves have found an excess of girls with mild asthma.

We do not know of any other study reporting on the relation of children with asthma to family size and position. In our study, the tendency for severe asthma to occur in children of families of 4 or more was present in all social classes, and there was a similar tendency for these children to be the second child in the family $(P<0.05)$.

We have thus found that Aberdeen children experiencing severe asthma tend to come from large families, whatever their social class, and that severe asthma occurs particularly in social classes IV and V; this is in sharp contrast to the concept of the child with asthma coming mainly from the professional classes.

Intelligence. Our studies confirm the belief that children with asthma are more intelligent than their peers. The IQs of the children with asthma were higher than those of the control population through all social classes, but it was in social classes IV and V that this was most apparent. Graham et al. (1967) reported a similar result from the Isle of Wight survey. The children in that study were given tests of intelligence (nonverbal) and tests of sentence reading and mechanical arithmetic: the children with asthma scored higher than the control group in all tests, the tendency being greatest in the group nonverbal test and less notable in the tests of educational attainment-reading and arithmetic. This is what one would expect from children, a large proportion of whom had missed a considerable amount of schooling. The Aberdeen study showed that the majority of children with asthma have relatively poor school attendance, particularly in their early school years; the more severe the asthma, the longer the total period of absence from school. The loss of schooling falls most heavily on those least able to make good the loss, namely severely affected child- ren coming from the lower social class families where help at home with school work is unlikely to be available.

Personality. The personality of the child with asthma is difficult to define without detailed psychological and psychiatric assessment. Some indication of neurotic behaviour and psychiatric difficulty was obtained by the use of the Aberdeen-London Behaviour Scale A, completed by the parents. The number of children scoring over the cut-off point which has been found to produce the best differentiation of children with psychiatric disorder was $8 \%$, almost the same as that for the general population (7\%). This differs from the Isle of Wight study, in which $10 \%$ of children with asthma scored over this point, though even this excess was not statistically significant (Graham et al., 1967). After interviewing parents and children and examining data from family doctors and hospital records, we concluded that only 2 of our children with asthma had definite psychiatric disorders. A number of the children had disturbed patterns of sleep, usually attributed by parents and child to the asthmatic attacks.

The personality of any child is affected to some degree by the attitude of his parents towards him and towards life in general. We tried to assess this in our asthma group by looking at the parents' ambitions for the careers of their children. The answers were generally similar to those in the control group. However, slightly more parents of children with asthma said they would prefer a job with 'good pay' to either 'a secure job' or 'one with good prospects of advancement', and slightly more thought that corporal punishment should be retained and that there should be segregation of the sexes in secondary schools. Perhaps this does reflect a rather more rigid, orthodox, and overprotective personality.

\section{Conclusion}

We have shown that children with asthma come from all social classes, but that a child in social class IV or V is more likely to have severe asthma than his peer in social class I or II. A possible explanation is that the child of social class I or II parents is more likely to receive early and vigorous treatment and is less likely to be exposed frequently to infection, so that the asthma does not become so severe. Parents in the nonmanual class are more likely to be aware of the implications of the child's first attack of wheezing and to seek medical advice early; they are also better equipped intellec- 
tually to understand the problem and to give the child the benefit of their resources.

As far as educational achievement is concerned, it appears that the child with asthma is relatively well endowed with intelligence to help him overcome his handicap and make good his interrupted education. While Graham et al. (1967) found that children with asthma were not over-achieving in relation to their level of general intelligence, it is surprising how much drive many of these children have to maintain their position in class despite their disability. Williams (1952) undertook a study of allergic disease in university students at the universities of Cambridge and Wales, and found a prevalence for asthma of $4.6 \%$ of the student population. This suggests that many children with asthma ultimately attain university entrance.

We are grateful to Professor R. Illsley and Dr. G. Horobin of the MRC Medical Sociology Research Unit, Aberdeen, for their help and advice in the preparation of this paper.

\section{REFERENCES}

Arbeiter, H. I. (1967). How prevalent is allergy among United States school children? Clinical Pediatrics, 6, 140.

Broder, I., Barlow, P. P., and Horton, R. J. M. (1962). Epidemiology of asthma and hay fever in a total community. Fournal of Allergy, 33, 513.
Dawson, B., Horobin, G., Illsley, R., and Mitchell, R. (1969). A survey of childhood asthma in Aberdeen. Lancet, 1, 827. Dubo, S., McLean, J. A., Ching, A. Y. T., Wright, H. L., Kauffman, P. E., and Sheldon, J. M. (1961). A study of relationships between family situation, bronchial asthma, and personal adjustment in children. Fournal of Pediatrics, 59, 402.

Briksson-Lihr, Z. (1955). Special features in allergy in children. Acta Allergologica, 8, 289.

Freeman, G. L., and Johnson, S. (1964). Allergic diseases in adolescents. American Fournal of Diseases of Children, 107, 549.

Graham, P. J., Rutter, M. L., Yule, W., and Pless, I. B. (1967). Childhood asthma: a psychosomatic disorder? British Fournal of Preventive and Social Medicine, 21, 78.

Kraepelien, S. (1954). The frequency of bronchial asthma in Swedish school children. Acta Paediatrica, 43, Suppl. 100, 149.

Peltonen, M. L., Kasanen, A., and Peltonen, T. E. (1955). Occurrence of allergic conditions in school children. Annales Paediatriae Fenniae, 1, 119.

Rutter, M., Tizard, J., and Whitmore, K. (1970). (Editors.) Education, Health and Behaviour. Longman, London.

Smith, J. M. (1961). Prevalence and natural history of asthma in school children. British Medical fournal, 1, 711.

Smith, J. M., Harding, L. K., and Cumming, G. (1971). The changing prevalence of asthma in school children. Clinical Allergy, 1, 57.

Williams, D. A. (1952). Social importance of allergic diseases. In Proceedings of the First International Congress for Allergy. Ed. by A. S. Grumbach. Karger, Basle.

Williams, H., and McNicol, K. N. (1969). Prevalence, natural history, and relationship of wheezy bronchitis and asthma in children. British Medical fournal, 4, 321.

Correspondence to Professor R. G. Mitchell, Department of Child Health, 11 Dudhope Terrace, Dundee DD3 6HG. 